\title{
THE ANALYSIS OF PUBLIC TRANSPORTATION SYSTEM IN SERANG, BANTEN
}

\author{
Rahman Abdullah $^{1}$ and M. Fakhruriza Pradana ${ }^{2}$ \\ ${ }^{1}$ Department of Civil Engineering, University of Sultan Ageng Tirtayasa, Province of Banten, Indonesia. \\ ${ }^{2}$ Department of Civil Engineering, University of Sultan Ageng Tirtayasa, Province of Banten, Indonesia. \\ ${ }^{1}$ rahman.abdullah@untirta.ac.id \\ 2mfakhruriza@yahoo.com
}

\begin{abstract}
The urban public transportation in Indonesia is still bad as it is not reliable, discomfort and insecure. One of the many reasons is because the public transport used is still largely dominated by small-capacity transport. This condition consequently resulted a heavy traffic jam and chaos. This bad public transportation can be found, for instance, in the city of Serang, the province of Banten. However, in the city of Serang, the problems seem to be more associated with a lower carrying capacity and routes. This study aims at examining the conditions of public transportation systems and estimating the performance indicators of public transport in the city of Serang, Province of Banten. Based on the observation, primary data and secondary data, the study found that the performance indicator in this city was quite good especially for the routes $01,02,03,04,05,06$ and 08 . While the routes 07 and 09 were relatively at an average performance. In terms of the indicators of service performance, however, the study found that the speed record for the trip, headway, travel time, frequency and waiting time need to be improved. Due to these findings, this study suggests that the local government needs to empower the public transportation rules and regulation. This is important partly to make the people obey the transportation routes so as to ensure the availability of transport. Also, there is a need to create a bigger and more comfortable vehicles such as bus or Light Rail Transport (LRT) facilities. Thus, much remain to be done by the government of the Serang City, Banten Province.
\end{abstract}

Keyword: public transportation, urban areas, indicator of service performance, transportation routes.

\section{INTRODUCTION}

The performance of urban public transportation in Indonesia is still bad and unreliable. The reason is partly because public transport operated is still largely dominated by small-capacity transport. Consequently, this type of transportation vehicles results traffic jam and chaos. This condition is no exception for the urban public transport in the city of Serang, the capital of city of the province of Banten. The population in this capital city can be considered densely populated with the growth rate at average $1.13 \%$ per year since 2010 . On the basis of the population number, this city was grouped into the category of medium-sized city.

This study based on observation and secondary data aims to examine the following two issues. The first is to obtain an overview of the management and the existing public transport system in the city of Serang, the province of Banten. The second is to develop a set of management strategies of public transport in the city of Serang that can provide viable and sustainable services. However, before these two issues are examined, the following section will deal first with the literature review of the ideal concept of the public transportation system in section 2. Section 3 highlights the research methodology. Section 4 analyzed the findings of the study. Finally, concluding remarks is drawn in section 5.

\section{LITERATURE REVIEW}

The public transport system is basically formed from a set of hardware which consists of the main infrastructure systems and facilities. Furthermore, both the hardware components are operated with the operating system or software system that consists of components such as frequency and fares (Santoso, 1996).

The components of the infrastructure and public transport itself, among others consist of the following. The first is public transport infrastructure components. This includes the network system, terminal, track along the right of way on each route, and stop. The second is public transportation components including type of vehicles used and the dimensions and the design of the vehicle.

In many cities, especially in Indonesia, both large and medium cities, have problems on public transport. These problems at least are the following. The first is that there are many communities that still cannot served by public transport. The second is that the travel fares are considered relatively high or expensive. The third is that vehicles used is still discomfort as they are old vehicles. Finally, the security and the safety aspects of trips are not reliable (Department of Transportation, 2007). 
According to the Transportation Minister Decree Number 35/2003 on the Implementation of Transport People on the Road, it was stated that a route was defined as the direction of transport vehicles from one place to other places, lines, and a scheduling. In this regulation it was also stated that in case of the need to add more vehicles, consideration toward the following conditions are important. These conditions are as follows.

a. Number of round-trip per day on average;

b. The average number of seats the vehicle;

c. Realization reports a load factor;

d. A load factor of $70 \%$;

e. The availability of appropriate terminal facilities;

f. Level of service

In terms of the structure of fares, several options are commonly used. These are uniform rates (flat fare) and distance based fare. However, for public transport vehicles that operate based on time, there are some patterns applied. The first is based on the timing of the operation. This is for passengers who travel at certain hours. In other words, passengers who travel at night will be served by the night of the public transport, while for passengers who travel at day time will be served by the daylight time public transport. The second is the public transport with no time schedule. Thus, this public transport operates for 24 hours without stopping so that people will have access to travel at any time.

Standards set by the Asian Development Bank (ADB, 2014) can be used as a reference to the government in developing the public transport system. These suggested standards are as follows:

1. For travel time, it was suggested that for the big cities or metropolitan areas a faster public transport vehicle is required to attract private motorists to use public transport

2. The travel fares using public transport should be cheaper than using a private car or taxi as these travel fares can be used as incentives for private motorist to use public transport.

3. For operating time, it was suggested that public transport operation begins at 6:00 to 22:00 or 16 hours. Standard using 12-hour option may be appropriate for certain cities according to the local transport context.

4. For the waiting time of passengers, it was suggested it is under eight minutes or between 0-15 minutes.

\section{RESEARCH METHODS}

As mentioned at the outset, the methods used to examine the research questions are shown at Figure 1. Before collecting the data and information, the study first identified the research problems. This research problems was constructed based on the problems faced in Serang City and by reading relevant literature published in Indonesia. After doing the literature review, a preliminary survey was conducted by undertaking personal observation and in-depth interview with the Transport office in the city of Serang. In this transport office, published secondary data were collected, especially regarding route characteristics, vehicle characteristics and traffic management. Primary data were collected by undertaking Focus Group Discussion (FGD) with passengers and the drivers of public transport. The information and data discussed include the load factor, speed, headway, time and the travel frequency of the public transport. 


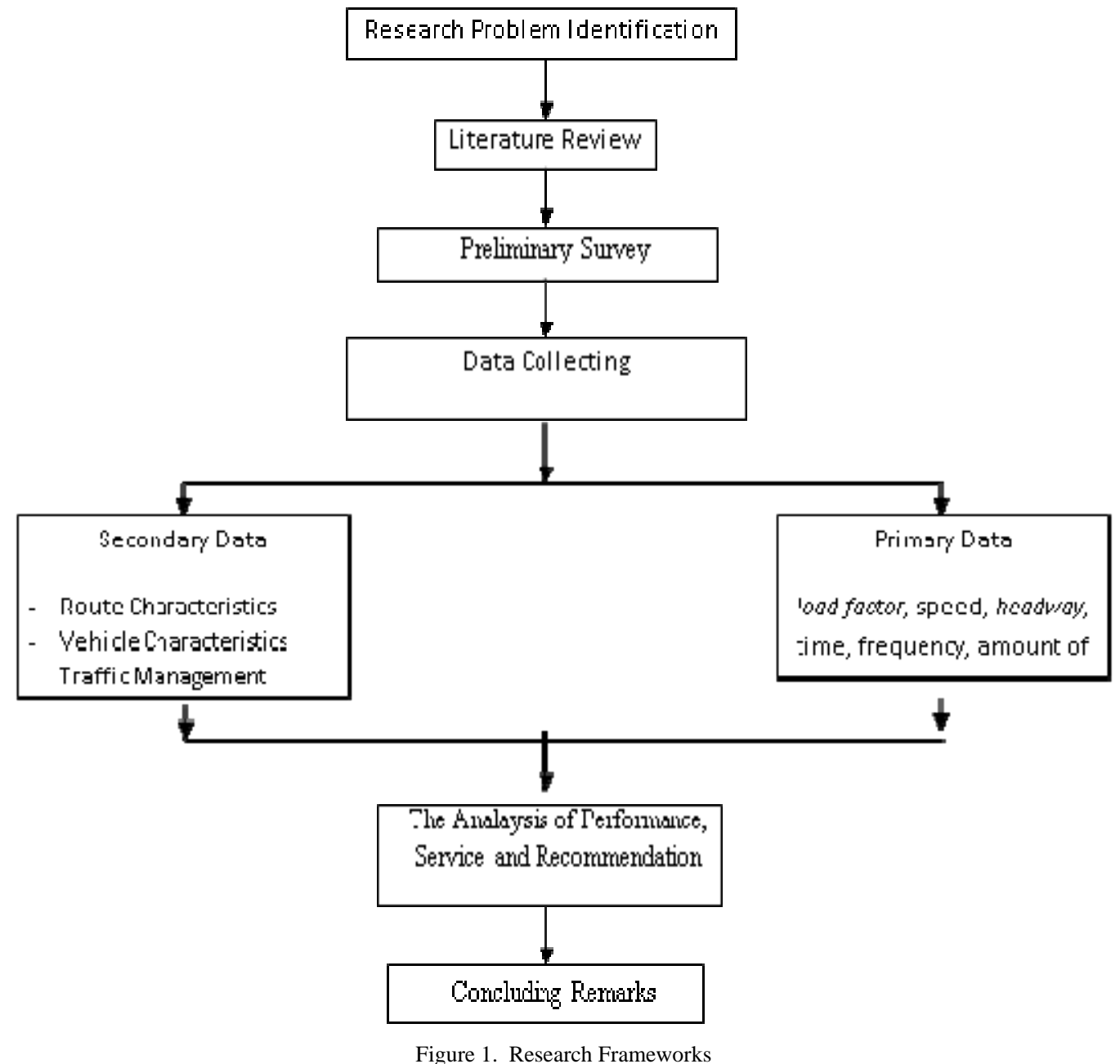

\section{A. General Description}

\section{FINDINGS AND ANALYSIS}

In accordance with the decree of Mayor Attack Number: 551.23 / Kep.74-Huk / 2009 on the establishment of Public Transport Route Network in Serang city, public transport division is distinguished by number, color and trajectory. The trajectory of public transport should not be more than 10 stretches and it should have transport capacity up to 12 passengers per vehicle.

The route which has a fleet of large amounts is the route no $01,02,03,04$ and 07 , while the route with a fleet of small amounts is the route no $05,06,08$ and 09 . The route no 10 , however, does not have any fleet as this fleet operate in urban areas. However there are problems associated with this fleet. These problems include in disciplinary, over capacity of passengers and usually the fleet do not have good management. Therefore, the public transportation in this city of Serang is not well managed by the regional government.

\section{B. Public Transportation Performance}

In the context of the performance of public transportation, using the measurements suggested by the ADB (2014) stated above the study found that the route No. 01 to No. 06 and No. 08 route has good service performance, but there are indicators in the unfavorable category that is on indicator frequency and travel time especially on the route No. 08 . Therefore, the route no 08 needs to be improved by adding the number of operating transport vehicles. Also, there should be the necessary improvements to the public transport journey times.

In terms of the service performance, the study found that there should be improvement toward the headway, travel time and frequency for the route No. 07 and 09. These can be done by adding the fleet on this route to increase the third indicator. However, in the context of stretch the worst performance is occupied by the route no 10 . The performance indicators that are categorized as less is travel speed, headway, travel time, frequency and waiting time. To improve the performance of the service of urban transportation route No. 10, it is suggested to divide the transport route into two routes. 


\section{Public Transport Performance Based on Mode Selection Parameters}

Based on Mode Selection parameters, the study found that there are at least six factors that need to be improved. These six factors are as follows. First, it relates with safety conditions both of drivers and criminalities of the public transports. Second, it relates with the speed of the vehicles. The third factor relates with road infrastructures. The fourth is associated with comfortable factor by providing, for example, car air condition. The fifth relates with the reasonable fare rates so as to minimize the use of private motor bikes and cars. Finally, it relates with the availability of vehicles for any routes. This is important to guarantee any passengers to have access public transport at any time.

Based on the above examination, this study suggests that the regional government needs to improve the following aspects. First, there should be Improvement in the performance of public transport by improving travel speed indicator, headway, travel time, frequency and route no waiting time at 07, 09 and 10 . Secondly, the government need to enforce the laws against public transport that does not obey the routes that have been determined as well as ensuring the availability of transport on the overall route. The third is by creating a public transport with greater capacity and more comfortable such as bus or LRT and accommodating the existing public transit riders to be a rider on a new transport. These conditions will have an impact on improving the speed, road infrastructures, smoothness and comfort of public transport as well as a reasonable fare rates. The fourth suggestions will be the establishment of companies or profit organization that are able to well manage the public transportation. The fifth is by improving supervising and intensifying coordination between the government and the private organization that managed the public transportation. Finally, there is a need to establish Plan development consistently and perform Monitoring and Evaluation (M \& E) periodically.

\section{CONCLUSION}

Serang City has 10 public transport routes serving the movement of passengers. From the calculation results based on the performance of the public transport service indicator, it was found that routes 01 to No. 06 and No. 08 have good service performance, but there are indicators in the unfavorable category especially the indicator of frequency and travel time. Therefore, the government needs to increase the number of public transport vehicles in operation, as well as improvements in terms of the public transport journey times.

In terms of the evaluation of the service performance, the study found that the headway, travel time and frequency particularly for the route No. 07 and 09 need to be improved by adding the fleet on this route. Whilst for the route no 10 , the study suggests that the government should divide the transport route into two routes.

In summing up : the public transport in the City of Serang, Banten Province should be improved in accordance the standard qualification of public transport system. These improvements consist of six dimension, namely, safety standards, speed, infrastructures, confortable, reasonable fare rates, and the availability of the vehicles to support guarantee for the people to have public transportation services. Thus, much remain to be done by the government and other stakeholders in the City of Serang to improve the public transportation system in the city of Serang in particular and in Indonesia in general.

\section{REFERENCES}

[1] Central Bureau of Statistics, City of Serang in Figures. BPS, City of Serang, Province of Banten, 2012.

[2] Department of Transportation, Public Transport problems in Indonesia. Jakarta, 2007.

[3] Malik, Ilham . "Public Transport Policy Analysis of Bandar Lampung. M. Eng.Thesis. University of Lampung, 2011

[4] M. Dinar, "Performance Evaluation City Transport Services in Serang (Case Study: Transport Route No. 01 and No. 02), unpublished thesis, University of Tirtayasa, Serang, Banten, 2014.

[5] Ministry of Transportation, Decision of the Director General of Land No. SK.687 / AJ.206 / DRJD / 2002 on Technical Guidelines for the Implementation of Public Transport in Cities In Fixed Route and Organized, Jakarta, 2003.

[6] Ministry of Transportation, Minister of Transportation Decree No. Km. 35 Year 2003 on the Implementation of Transport People On Road With General Vehicle, Jakarta, 2003.

[7] Ministry of Transportation, Transport Minister Regulation No. 98 of 2013 About Minimum Service Standards People with Motor Vehicle Transport General in Route, Jakarta, 2013.

[8] Ministry of Transportation, Transport Minister Regulation No. 46 of 2014 About Minimum Service Standards People with Motor Vehicle Transport General Not in Route, Jakarta,2014.

[9] Ministry of Transportation, Government Regulation No. 43 of 1993 (43/1993) About Infrastructure and Road Traffic, Jakarta, 1993.

[10] M. F. Pradana and Bethary, Rindu Twidi. "Elections Public Transport Mass in the City of Serang Using Analytic Hierarchy Process (AHP)”, University of Tirtayasa, Serang Banten, 2011.

[11] S. Idwan. Public Transport Infrastructure Planning. Center for the Study of Transport \& Communications Bandung Institute of Technology (Series 002), 1996.

[12] Regional Department, SK Walikota Serang No: 551.23 / kep.74-Huk / 2009 on Establishment of Public Transport Route Network in Serang, Banten, 2009.

[13] Susantono, 1001 Transportation We Face. Scholastic Press, Jakarta, 2009. 